\title{
Preliminary Experimental Study on Heat Transfer Characteristics of Wall with Automatic Adjustment of Heat Transfer Coefficient
}

\author{
Zhiyong $\mathrm{Li}^{1, \mathrm{a}^{*} \text {, Liyang Zhang }}{ }^{1, \mathrm{~b}}$, Yuqing Zhao ${ }^{1}$, Ye $_{\text {Zhang }}{ }^{2}$ and Qianqian Shi ${ }^{1}$ \\ ${ }^{1}$ College of Civil Engineering, North China University of Technology, Shijingshan, Beijing, China, \\ 100144 \\ ${ }^{2}$ College of Architecture Engineering, Xinjiang University, Tianshan, Wulumuqi, China, 830046 \\ a lizhiyongnbe@163.com, ${ }^{\mathrm{b}}$ flyingu@126.com
}

\begin{abstract}
Keywords: Automatic adjustment of heat transfer coefficient, Wall, Bimetallic strip, Experimental study
\end{abstract}

Abstract. A wall with auto-adjusted heat transfer coefficient based on the outdoor temperature is introduced. The mechanism of the bimetallic strip wall with auto-adjusted heat transfer coefficient was given. The thermal performance of the variable thermal resistance layer in different conditions was preliminary tested. The results show that when the temperature of the heating layer is steady at about $40^{\circ} \mathrm{C}$, under the high and low thermal resistance conditions, the mean heat transfer coefficient of the variable thermal resistance layer is about 11 $\mathrm{w} /\left(\mathrm{m}^{2} \cdot \mathrm{K}\right)$ and $15 \mathrm{w} /\left(\mathrm{m}^{2} \cdot \mathrm{K}\right)$ respectively. The function of automatic adjustment of heat transfer coefficient of wall has been preliminarily achieved. The maximum change rate of the heat transfer coefficient of the wall is $36 \%$. This paper provides fundamental base for the further research.

\section{Introduction}

The building envelope has an important influence on the construction of energy saving. The building wall is the main interface and the main channel for heat exchange, between the inside and the outside building environment. Therefore, to reduce the energy consumption of walls, is one of the main methods to reduce building energy consumption. However, at present, the main external insulation form of the building exterior wall is exterior insulation, internal insulation, sandwich insulation and composite insulation ${ }^{[1-3]}$. The wall heat transfer coefficient is almost constant. Most areas of northern China are continental climate, which has a large diurnal temperature range. In these areas, outdoor temperature is usually carried out in a large range of fluctuation. For example, in summer, the situation of outdoor temperature is higher than the indoor at daytime, or the outdoor temperature is below indoor temperature at night, that is occur frequently. As a result, these areas' summer, the low wall heat transfer coefficient of the building at night, hardly to use the outdoor hot or cold source (outside cold air, sky radiation, etc.) for cooling. In this paper, the automatic adjustment of heat transfer characteristics of wall is proposed to solve this problem. As an example in summer, when the outdoor temperature is higher than the indoor, the heat transfer coefficient of the wall becomes smaller automatically, then the heat transfer through the wall is reduced. When the outdoor temperature is lower than the indoor, the heat transfer coefficient of the wall becomes higher automatically, then the heat conduction through the wall to the outside is increased. The variable heat transfer coefficient wall can be automatically adapted to the characteristics of outdoor air temperature variation, further reduce the energy consumption of building envelope.

This paper proposes a bimetallic strip automatic adjustment of heat transfer coefficient of the wall structure, and introduces the principle of regulating the heat transfer coefficient of the wall, and the preliminary experimental of heat transfer characteristics of the thermal resistance layer of the wall were studied.

\section{The principle of automatic adjustment of wall heat transfer coefficient}

In this study, the wall of heat transfer coefficient auto adjusting structure is shown in Fig. 1. The wall is mainly composed of a surface protective layer (1), variable thermal resistance layer (2), bearing layer (3) 
formed. Among them, variable thermal resistance layer is the major part of the wall. The bimetallic strip is a composite material consisting of two or more metal or other materials with suitable properties. Because of the different expansion coefficient of the material, when the temperature changes, the bimetallic strip will bend towards one side overall. The working principle of variable heat resistance wall is: in summer, when the outdoor temperature is higher than indoor, the surface layer (1) is heated, so that the bimetallic strip's temperature (4) is raised, then bending. The separation of the bimetallic strip (4) and the corresponding flexible thermally conductive substrate (5). So that the variable thermal resistance layer (2) only air thermal, as the result of the thermal resistance is the largest and the heat transfer coefficient is the smallest. Then the energy consumption of buildings has been reduced. When the outdoor temperature is lower than the indoor temperature, bimetallic strip (4) downward deflection until close to the corresponding flexible thermally conductive substrate (5). As the results is reducing the variable thermal resistance layer resistance. At this point through the wall of the heat conduction to the outside is great, and reduced the air conditioning energy consumption. In winter, when the temperature is lower, the bimetallic strip will continue to downward deflection, to realize the separation of the thermal conductivity of the substrate. At this point, the thermal resistance layer (2) only within the air conduction, the thermal resistance is maximum, and the heat transfer coefficient is minimum, this time through the wall to the outside of the heat conduction is minimum. In the transition season, variable thermal resistance layer is automatically adjusted according to the outdoor temperature.

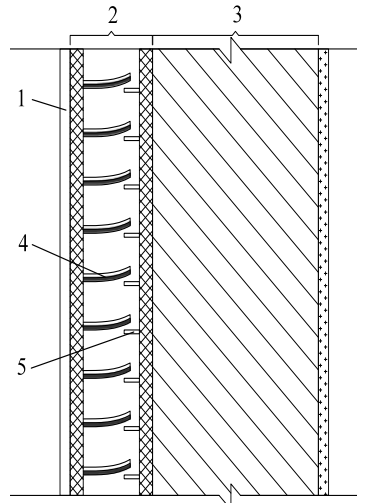

Fig. 1 The principle of automatic adjustment of wall heat transfer coefficient (high thermal resistance condition)

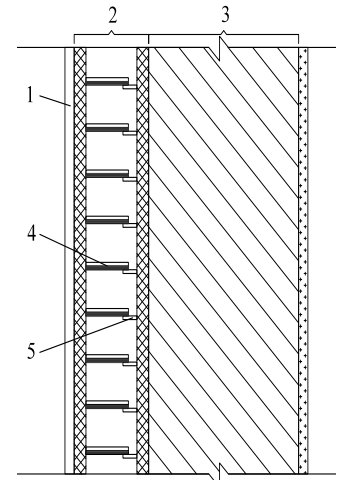

Fig.2 The principle of automatic adjustment of wall heat transfer coefficient (low thermal resistance condition)

In Fig. 1 and Fig. 2, the list of the common serial numbers is as follows: 1. Surface protective layer, 2. Variable thermal resistance layer, 3. Bearing layer 4. Bimetallic strip, 4. Bimetallic strip, 5. Flexible thermally conductive substrate

\section{Experimental setup}

\section{Experimental platform construction}

In order to test the heat transfer characteristic of variable thermal resistance layer, we set up the experimental platform in this study, and the test bench is set up as shown in Fig. 3, Fig. 4. Experimental platform mainly consists of the heat insulating layer, a heating layer, bimetal interlayer or air interlayer, the hypolimnion and data acquisition system. The experiment is divided into two kinds of working conditions:

high thermal resistance condition

The high thermal resistance operating condition test bench is set in Fig. 3. The experiment process is: the first electric heating layer electricity, heating temperature gradually increased, due to the heating layer and the hypolimnion temperature difference, heat transfer from the heating layer to the hypolimnion and hypolimnion temperature began to gradually increased, after a period of time, heating temperature reaches a steady, heat flow also to stabilize. When the temperature in the heating layer is stable at about $40{ }^{\circ} \mathrm{C}$, hypolimnion 
temperature in more than 1 -hour time stable within $1{ }^{\circ} \mathrm{C}$ that the experiment reaches the steady state, ending the experiment.

low thermal resistance condition

The experimental table of low thermal resistance condition is shown in Fig. 4. The experimental process is similar to the experimental process of high thermal resistance condition.

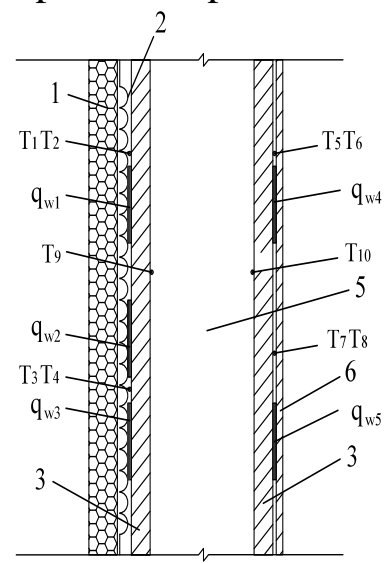

Fig. 3 Principle of automatic adjustment of

heat transfer coefficient of wall variable thermal resistance layer

(high thermal resistance condition)

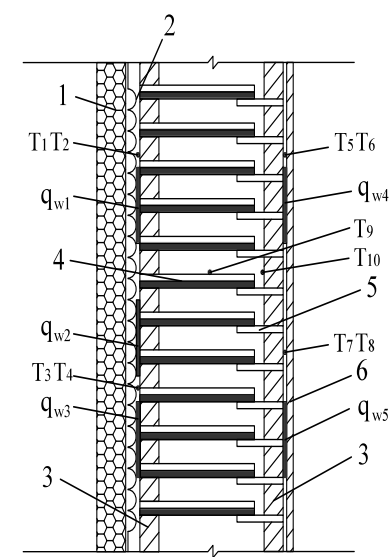

Fig. 4 Principle of automatic adjustment of heat transfer coefficient of wall variable thermal resistance layer (low thermal resistance condition)

In Fig. 3 and Fig. 4, the list of the common serial numbers is as follows: 1. Insulation layer, 2. Heating layer, 3. Supporting structure, 4. Bimetallic strip, 6. Hypolimnion, 7. $\mathrm{T}_{1} \sim \mathrm{T}_{10}$ temperature measuring point, 8 . $\mathrm{q}_{\mathrm{w} 1} \sim \mathrm{q}_{\mathrm{w} 5}$ heat flux sensor. The serial numbers 5 is Pure air interlayer in Fig. 3 and Flexible thermally conductive substrate in Fig. 4.

By high and low thermal resistance condition experimental, analysis and comparison of the two conditions of heat transfer coefficient, heat flux, the heating layer and hypolimnion temperature changes with time. Concluded that the change of the law of heat transfer about the variable thermal resistance layer and the change of heat transfer coefficient.

\section{Layout of measurement points}

In order to monitor the heat flow density and temperature in the heat transfer characteristics of the heat transfer layer in real time, the data acquisition system is set up in this experiment. In the two kinds of experimentalconditions, the heating layer and hypolimnion each arranged four temperature measuring points (Heating layer temperature measuring point $\mathrm{T}_{1} \sim \mathrm{T}_{4}$, Hypolimnion temperature measuring point $\mathrm{T}_{5} \sim \mathrm{T}_{8}$ ), Bimetal interlayer or air interlayer arrangement of two temperature measuring points $\left(\mathrm{T}_{9}, \mathrm{~T}_{10}\right)$; Heat flux sensor in the heating layer is arranged three $\left(\mathrm{q}_{\mathrm{w} 1} \sim \mathrm{q}_{\mathrm{w} 3}\right)$, in hypolimnion is arranged two $\left(\mathrm{q}_{\mathrm{w} 4} \sim \mathrm{q}_{\mathrm{w} 5}\right)$. Use data logger for 10 temperature measurement points monitor automatically records each time one-minute interval; the use of heat flow tester 5 heat flux sensors monitored every 3 minutes' interval manual recording time.

The various instruments and related materials used are as follows: 1. Data logger, Agilent 34970A. 2. Multi channel temperature and heat flow meter, JTNT-A/C, Heat flow measurement accuracy $\pm 5 \%$. 3 . Thermocouple is T Type, $\pm 5^{\circ} \mathrm{C}$. 4. Heat flux sensor, JTNT-A/C, Heat flux testing range $0 \sim 2000 \mathrm{w} /\left(\mathrm{m}^{2} \cdot \mathrm{K}\right)$.

\section{Data processing}

(1) The average heat flux of heating layer is $q_{w}$ :

$$
\mathrm{q}_{\mathrm{w}}=\left(\mathrm{q}_{\mathrm{w} 1}+\mathrm{q}_{\mathrm{w} 2}+\mathrm{q}_{\mathrm{w} 3}\right) / 3 \text {. }
$$

(2) Heat insulation temperature difference is as follows, $\triangle \mathrm{t}$ :

$$
\begin{gathered}
\mathrm{T}_{\mathrm{a}}=\left(\mathrm{T}_{1}+\mathrm{T}_{2}+\mathrm{T}_{3}+\mathrm{T}_{4}\right) / 4 . \\
\mathrm{T}_{\mathrm{b}}=\left(\mathrm{T}_{5}+\mathrm{T}_{6}+\mathrm{T}_{7}+\mathrm{T}_{8}\right) / 4 . \\
\triangle \mathrm{t}=\mathrm{T}_{\mathrm{a}}-\mathrm{T}_{\mathrm{b}} .
\end{gathered}
$$


(3) The resistance of the variable thermal resistance layer is $1 / \mathrm{AK}$ :

$$
1 / \mathrm{AK}=1 /(\mathrm{Aq} / \triangle \mathrm{t})=\triangle \mathrm{t} / \mathrm{Aq}
$$

(4) Heat transfer coefficient of thermal insulation structure is $\mathrm{K}$ :

$$
\mathrm{K}=\mathrm{q} / \triangle \mathrm{t}
$$

$\mathrm{q}_{\mathrm{w} 1} \sim \mathrm{q}_{\mathrm{w} 3}$ is three heat flux measuring points in the heating layer $\left(\mathrm{w} / \mathrm{m}^{2} \cdot \mathrm{K}\right), \mathrm{T}_{1} \sim \mathrm{T}_{4}$ is four temperature measuring points in the heating layer $\left({ }^{\circ} \mathrm{C}\right), \mathrm{T}_{5} \sim \mathrm{T}_{8}$ is four temperature measuring points of the hypolimnion $\left({ }^{\circ} \mathrm{C}\right), \triangle \mathrm{t}$ is heat transfer temperature difference $\left({ }^{\circ} \mathrm{C}\right), \mathrm{A}$ is heat transfer area through the actual measurement $\mathrm{A}=0.14175\left(\mathrm{~m}^{2}\right)$.

\section{Experimental result analysis}

Variable thermal resistance layer heat transfer characteristics were tested under two different conditions, heat flux density $\mathrm{q}_{\mathrm{w}}$, heating layer temperature $\left(\mathrm{T}_{\mathrm{a}}\right)$, temperature layer temperature $\mathrm{T}_{\mathrm{b}}$ and heat coefficient $\mathrm{K}$ of changes with time, the results shown in Fig. 5, Fig. 6, Fig. 7 and Fig. 8. In this paper, the experimental process is divided into: (1) at the beginning stage, (2) the transition stage, (3) the steady state stage, the experimental analysis of the two kinds of conditions are as follows.

\section{High resistance conditions in variable thermal resistance layer}

Fig. 5 shows that the beginning of the experiment stage (about 0 60 min), the rapid rise in temperature in the heating layer, hypolimnion temperature rise slowly, under the action of temperature difference, heat flow density mainly by temperature in the heating layer changes greatly; The transition phase (about 60 260min), the heating layer and the hypolimnion temperature increased slowly; The steady-state phase (about 260 410min), with the hypolimnion temperature rise accelerated, the heating layer and the hypolimnion temperature gradually decreases, heat flux density, heating temperature and hypolimnion temperature are basically unchanged. Experiment to achieve steady state of thermal resistance of variable thermal resistance layer.

According to the test data of 3 stages and the equation (6), the calculation results of the heat transfer coefficient are shown in Fig. 6.

According to the experimental data, the average heat transfer coefficient is $11 \mathrm{w} /\left(\mathrm{m}^{2} \cdot \mathrm{K}\right)$.

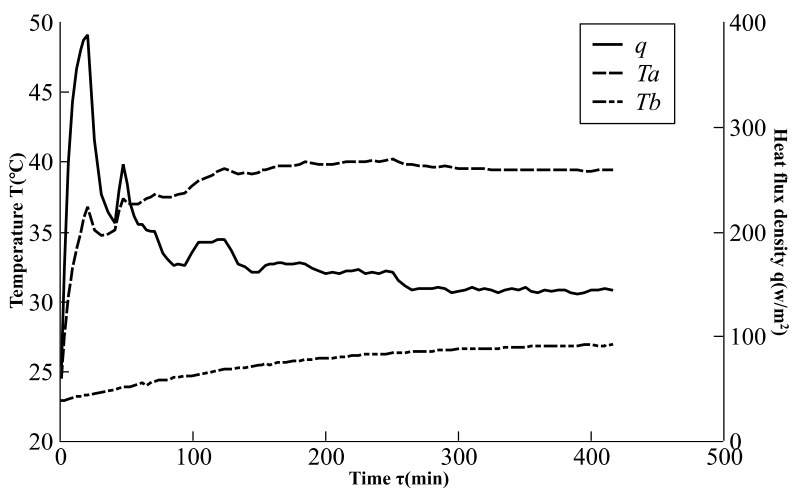

Fig. 5 The change of heat flux density q,

heating layer temperature $\mathrm{T}_{\mathrm{a}}$, hypolimnion temperature $\mathrm{T}_{\mathrm{b}}$ with time (high thermal resistance condition)

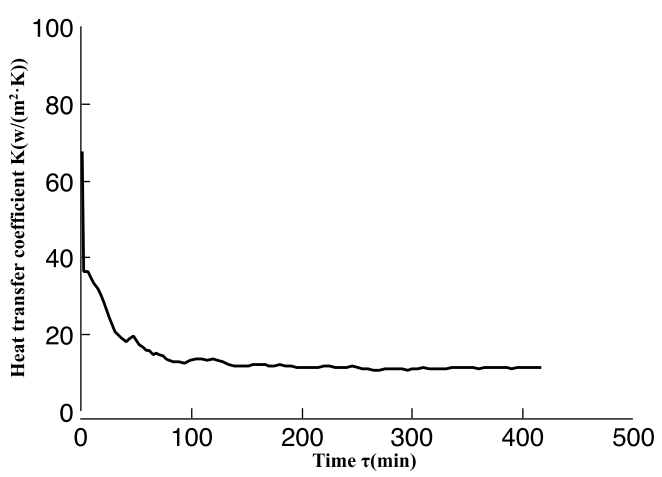

Fig. 6 Heat transfer coefficient $\mathrm{K}$ changes with time (high thermal resistance condition)

\section{Low resistance conditions in variable thermal resistance layer}

Fig. 7 shows the results of the experimental test under low thermal resistance, which can be found in Fig. 7 is similar to the variation of temperature and heat flux of the thermal resistance layer under low thermal resistance. According to equation (6), the calculation results of heat transfer coefficient are shown in Fig. 8.

According to the experimental data, the average heat transfer coefficient is $15 \mathrm{w} /\left(\mathrm{m}^{2} \cdot \mathrm{K}\right)$.

In the experimental of steady-state phase, the variable thermal resistance layer having a low thermal conditions with respect to the high thermal conditions, the heat transfer coefficient of variation was $36 \%$. 


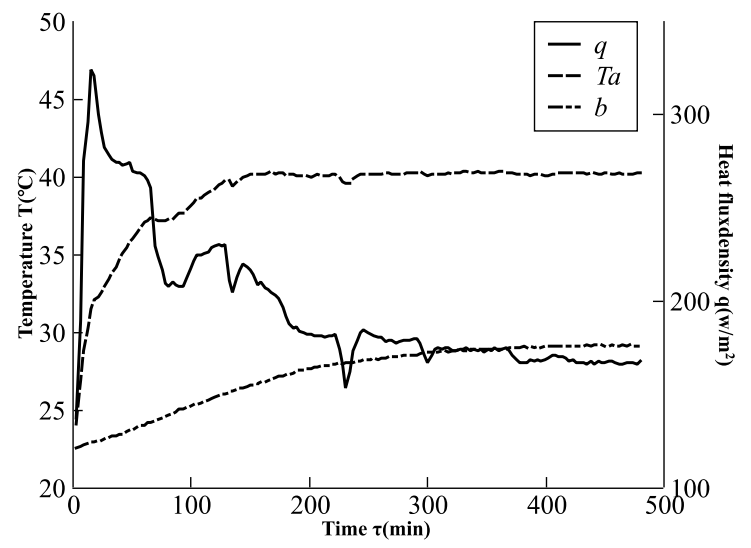

Fig. 7 The change of heat flux density q, heating layer temperature $\mathrm{T}_{\mathrm{a}}$, hypolimnion temperature $\mathrm{T}_{\mathrm{b}}$ with time (low thermal resistance condition)

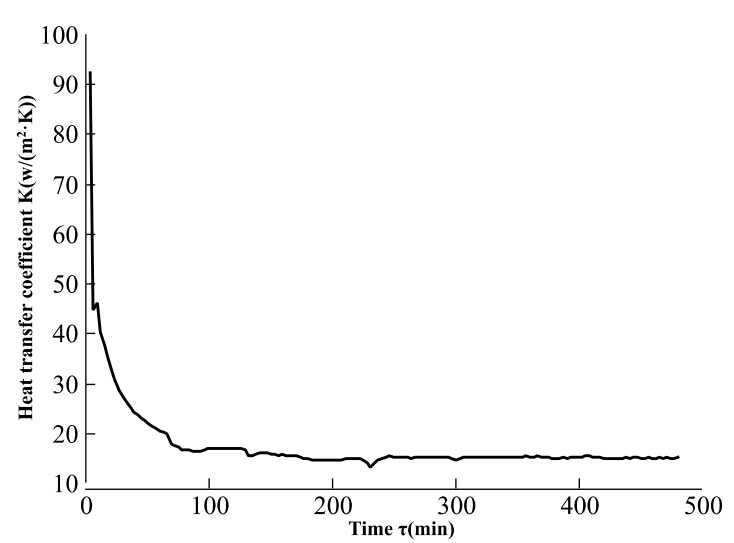

Fig. 8 Heat transfer coefficient $\mathrm{K}$ changes with time (low thermal resistance condition)

\section{Conclusions}

In this paper, the heat transfer characteristics of the thermal resistance layer under two conditions of high thermal resistance and low thermal resistance are preliminarily tested. In steady-state heat transfer phase, the average heat transfer coefficient in high resistance condition of variable thermal resistance layer is $11 \mathrm{w} /$ $\left(\mathrm{m}^{2} \cdot \mathrm{K}\right)$; the average heat transfer coefficient in low resistance condition of variable thermal resistance layer is $15 \mathrm{w} /\left(\mathrm{m}^{2} \cdot \mathrm{K}\right)$. Wall heat transfer coefficient change rate of about $36 \%$.

The study reached a preliminary wall heat transfer coefficient automatic adjustment purposes, but the wall heat transfer coefficient and the practical application of the rate of change there is a large gap, mainly due to the contact resistance of the bimetal strip and flexible thermally conductive substrate is too large, which is a problem in follow-up studies need to be resolved.

\section{Acknowledgements}

This research is supported and funded by the National Natural Science Foundation of China, and the project approval No. 51568060. In addition, this study has been supported and funded by the North China University of Technology "young talents cultivation plan".

\section{References}

[1] Zeping Zhang, Zhu Li, Yanli Dong. Review and Prospect of building energy-saving wall insulation, J. Engineering Mechanics, 2007, 24 (S2), pp. 121-128.

[2] Xinbo Pan. The summary of building exterior insulation technology and thermal insulation material, J. Jiangxi building materials, 2015, (08), pp. 15.

[3] Haijun Tan, Jiazhen Zhang, Chunyue Pan. Summary of energy-saving building materials, J. Building energy saving, 2009, (05), pp. 49-52. 